\title{
FARINHA DE CASCA DE OVO: DETERMINAÇÃO DO TEOR DE CÁLCIO BIODISPONÍVEL
}

\section{EGG SHELL FLOUR: DETERMINATION BIOAVAILABLE CALCIUM}

\author{
PERES; A. P.; WASZCZYNSKYJ², N. \\ ${ }^{1}$ Aluna do PPGTA e Professora do curso de Nutrição das Faculdades Integradas do Brasil, \\ email: andrea@linhalivre.com.br \\ ${ }^{2}$ Professora Doutora da UFPR, Programa de Pós-Graduação em Tecnologia de Alimentos. \\ REC: 03/09 AC: 04/09
}

\begin{abstract}
RESUMO:
O cálcio é um mineral de extrema importância para o ser humano. A ingestão adequada de cálcio, desde os primeiros anos de vida, garante melhor a densidade óssea. Desta forma, este trabalho teve por objetivo determinar a quantidade de cálcio biodisponível na farinha da casca de ovo para fins alimentícios. Para a elaboração da farinha, as cascas de ovos selecionadas foram lavadas, sanitizadas com hipoclorito de sódio a $2,5 \%$, e imersas em água a $80^{\circ} \mathrm{C}$ durante 10 minutos, submetidas à secagem em estufa com circulação de ar a $100^{\circ} \mathrm{C}$ durante 60 minutos, trituradas em moinho analítico, passadas em peneiras de malha $300 \mathrm{~mm}$, acondicionadas em recipientes de vidro esterilizados e, por fim congeladas a $-18^{\circ}$ C. Constatado de que o cálcio proveniente da farinha de casca de ovo é biodisponível, em $36,9 \%$ de cálcio, na forma íon absorvível pelo organismo. A farinha de casca de ovos submetida à análise microbiológica resultando em conformidade para os patógenos pesquisados de acordo com a RDC 12 da ANVISA.
\end{abstract}

Palavras-chave: casca de ovo, cálcio, carbonato de cálcio.

\begin{abstract}
:
Calcium is a important mineral for humans. Adequate intake of calcium, since earliest yeras of life, provides better boné density. Thus, this study aimed determine bioavailable calcium in the eggshell flour in food. For the flour preparation, eggshells were washed, sanitized with sodium hypochlorite $2.5 \%$, and immersed in water at $80^{\circ} \mathrm{C}$ for 10 minutes, dried in oven with air circulation at $100^{\circ} \mathrm{C}$ for 60 minuts, broken into analytical mill and passed through sieves of mesh $300 \mathrm{~mm}$, packed in sterile glass containers, and finally forzen at $-18^{\circ} \mathrm{C}$. Found calcium from the eggshell meal is bioavailable, in $36.9 \%$ of calcium ion in the form absorbable by the body. Flour eggshells subjected to microbiological analysis results in accordance to the pathogens according RDC 12 ANVISA.
\end{abstract}

Keywords: egg shell, calcium, calcium carbonate

\section{INTRODUÇÃO}

O cálcio é um macromineral encontrado em maior quantidade no organismo, o que corresponde a uma variação de $1,5 \%$ a $2 \%$ do peso corpóreo. Quase que a totalidade deste, ou seja, $99 \%$ estão presentes nos ossos e dentes. Este percentual, não é estático, pois ocorre a entrada e saída de cálcio nos ossos (GALISA, ESPERANÇA e SÁ, 2008).

Este mineral tem como função formar ossos e dentes, ajudar na coagulação do sangue, na transmissão nervosa, na contração muscular entre outras (GALISA, ESPERANÇA e SÁ, 
2008).

A perda de cálcio acontece diariamente pela urina, suor e fezes. Grande parte do cálcio consumido é absorvida pelo intestino delgado. Devido a isto, a absorção de cálcio além de influenciada pela ingestão dietética, pode também estar relacionada com a idade e as condições clínicas subjacentes como a má absorção intestinal (DE PAULA, 2004).

A deficiência de cálcio pode induzir a uma perda mineral óssea que poderá resultar numa osteoporose, raquitismo, osteomalácia ou tetania (NAVES; FERNANDES, 2007). Para evitar transtornos com a saúde a recomendação diária de cálcio varia de 800 até $1200 \mathrm{mg}$ conforme a idade e sexo. Sendo o máximo tolerável para o referido mineral é de $2.500 \mathrm{mg} / \mathrm{dia}$ (COZZOLINO, 2001).

Para indivíduos cujo consumo de alimentos ricos em cálcio encontra-se limitado, os alimentos fortificados e os suplementos de cálcio constituem uma alternativa para alcançar o consumo adequado (BRYANT; CADOGAN; WEAVER, 1999).

A casca de ovo é rica em minerais, tais como o carbonato de cálcio $(96 \%$ do peso da casca), carbonato de magnésio (1\%) e fosfato de cálcio (1\%) (NEVES, 1998), sendo que o cálcio está presente em maior quantidade, e é encontrado na forma de carbonato de cálcio na proporção de $40 \%$ biodisponível do produto em pó.

A industrialização de ovos (ovos em pó, líquidos ou congelados) proporciona vantagens econômicas, extensão da vida útil do produto, facilidades no transporte e conservação, porém, gera um número expressivo de cascas, sendo ainda classificadas como resíduos. Sabendo-se que a casca representa $10 \%$ do peso do ovo, o resíduo gerado corresponde a cerca de 5,92 milhões de toneladas por ano em todo o mundo (MURAKAMI et al., 2007; OLIVEIRA, 2009).

A casca do ovo serve como base para desenvolvimento de produtos na indústria cosmética, suplementos alimentares, bases biocerâmicas, fertilizantes, implantes ósseos e dentários, e como agentes antitártaro em cremes dentais (MURAKAMI, 2006).

É um resíduo pouco valorizado, mas que representa um valor econômico potencial. Aspectos ambientais devem ser considerados na valorização das cascas de ovo, pois, além de diminuir o problema de poluição, quando estas são descartadas diretamente no meio ambiente, contendo um teor considerável de proteínas, o uso destas cascas como fonte alternativa de $\mathrm{CaCO} 3$ (carbonato de cálcio) pode diminuir o impacto sobre as reservas naturais de rocha calcária, uma fonte natural não-renovável (OLIVEIRA, 2009).

Além do aspecto econômico, o cálcio proveniente da casca de ovo apresenta vantagens nutricionais, pois não está associado a elevadas quantidades de proteína e sódio que podem induzir a um aumento da excreção renal de cálcio (NAVES; FERNANDES, 2007).

O pó da casca de ovo é um dos componentes que fazem parte da multimistura utilizada na recuperação de crianças desnutridas. Há controvérsia sobre sua utilização como fonte de cálcio devido à presença de fatores antinutricionais, ou seja, fibras alimentares em grande quantidade diminuindo assim a biodisponibilidade dos minerais presentes na multimistura. Porém, o pó da casca do ovo pode ser utilizado em outros alimentos como suplementação desde que não existam estes fatores (SANT'ANA, 2000).

Alimentos de consumo habitual fortificados com a farinha da casca do ovo podem contribuir de forma significativa para a ingestão adequada de cálcio, contribuindo assim para a adequada ingestão do mineral pela população, prevenindo doenças relacionadas (LUFT, 2005).

Outra fonte alimentar de cálcio é o leite e seus derivados como os queijos, iogurtes, coalhada, bem como sardinha e algumas hortaliças verde-escuras (GALISA, ESPERANÇA e SÁ, 2008). 
Os alimentos podem ser enriquecidos também com sais de cálcio na forma de citrato de cálcio ou lactato de cálcio. Este último é uma opção viável para bebidas por ser solúvel, podendo ser aplicado pela indústria processadora de alimentos (PEDRÃO, 2008).

\section{OBJETIVOS}

2.1 Objetivo principal

Elaborar e caracterizar farinha de cascas de ovos

\subsection{Objetivos secundários}

Determinar a granulometria da farinha de cascas de ovos

Determinar e quantificar o cálcio biodisponível na farinha de cascas de ovos

Analisar a inocuidade da farinha de cascas de ovos

\section{MATERIAL E MÉTODOS}

\subsection{MATERIAL}

O material utilizado foram cascas de ovos brancos tipo extra de galinha, doados por uma padaria tradicional da cidade.

\subsection{MÉTODOS}

\subsubsection{Preparo da farinha das cascas de ovos}

O preparo da farinha foi realizado de acordo com Silva Junior (2005) e Naves (2003).

As cascas de ovos brancos tipo extra foram lavadas em água corrente, e em seguida foram sanitizadas em solução clorada a 200 ppm durante 15 minutos ( 3 litros de água com $12 \mathrm{~mL}$ de hipoclorito de sódio a $5 \%$ ). Após sanitização, as cascas foram imersas em água a $80^{\circ} \mathrm{C} \pm 2^{\circ} \mathrm{C}$ durante 10 minutos; a água foi descartada e as cascas enviadas para secagem em estufa com circulação de ar da marca Quimi modelo Q819V2 a $100^{\circ} \mathrm{C}$ por 60 minutos. Posteriormente, foram trituradas em liquidificador marca Metvisa modelo LQ15 e em moinho analítico Quimi modelo Q298A21. Homogeneizadas em peneiras de tamanho $300 \mathrm{~mm}$ e acondicionadas em recipientes de vidro esterilizados e mantidas a $-18^{\circ} \mathrm{C}$ até a realização dos testes.

\subsubsection{Análise microbiológica da farinha da casca de ovos}

A análise microbiológica foi feita de acordo com a Resolução $\mathrm{n}^{\circ} 12$, de 2 de janeiro de 2001 da ANVISA (BRASIL, 2001), conforme descrita a metodologia no APHA (1992), para contagem de Coliformes Totais e Fecais, Staphilococcus aureus, Clostridium perfringes, Bacillus cereus e Salmonella sp.

3.2.3 Determinação de cálcio da farinha da casca de ovos 
A determinação de cálcio da farinha das cascas de ovos foi realizada segundo a metodologia descrita no Instituto Adolfo Lutz (IAL) (1985), no método volumétrico, após digestão das amostras com ácido clorídrico e titulação com solução de EDTA, utilizando o calcon como indicador. Apresentando, como resultado, o carbonato de cálcio. Para a determinação de íon cálcio na forma absorvível pelo organismo foi considerado o peso molecular do carbonato e do cálcio puro. Encontrou-se o percentual de cálcio biodisponível por regra de três. Para tanto, em 100 $\mathrm{g}$ de carbonato de cálcio existe $40 \mathrm{~g}$ de cálcio.

Todas as análises realizadas em triplicata.

\section{RESULTADO E DISCUSSÃO}

\subsection{Determinação da granulometria da farinha das cascas de ovos}

A granulometria efetuada na farinha obtida das cascas de ovos demonstrou que $20 \%$ das partículas têm tamanho superior a $0,30 \mathrm{~mm}$, e os $80 \%$ restantes são de granulometria inferior a esta. Resultado este que se aproxima da farinha de trigo que apresenta $95 \%$ passante em $0,25 \mathrm{~mm}$ (ANACONDA, 2009).

O tamanho de partícula após a moagem do trigo, constitui um fator importante no preparo de massas alimentícias e panificados. Uma vez que uma maior uniformidade da granulometria permite a elaboração de um produto final de melhor qualidade sensorial, ao avaliar a textura, sabor e aspecto visual, pois o alimento absorve água de forma homogênea resultando consequentemente num cozimento uniforme da massa (SILVA et al, 2008).

\subsection{Determinação do teor de cálcio na farinha das cascas de ovos}

A farinha das cascas de ovos, neste estudo apresentou 39,9\% de cálcio na forma íon absorvível pelo organismo, ou seja, $39.900 \mathrm{mg}$ de cálcio em $100 \mathrm{~g}$ de farinha de casca de ovo. Resultado este ligeiramente superior ao obtido por Naves (2003) e Luft (2005) que foi de 36,8\%, ainda o primeiro pesquisador mencionou que a casca de ovo é composta essencialmente de carbonato de cálcio.

Para Naves (2007), o pó da casca de ovo continha $37,4 \pm 0,2 \mathrm{~g} .100 \mathrm{~g}(1,1 \%$ de umidade) de cálcio, tendo a casca de ovo in natura 32,2 g.100 g (15,1\% de umidade).

A utilização da casca de ovo na alimentação agrega valor, por ser fonte de sais minerais. E ainda, tem como vantagem de não conter elementos tóxicos (MURAKAMI, 2006).

O pó da casca de ovo, quando preparado de forma adequada, constitui uma fonte de cálcio de alto valor nutritivo e que pode contribuir de forma significativa para o aporte diário de cálcio, sobretudo das populações de baixa renda (NAVES, 2003).

\subsection{Análise microbiológica da farinha das cascas de ovos}

Na Tabela 2 encontra-se o resultado da análise microbiológica realizada na farinha das cascas de ovos. 
TABELA 2 - ANÁLISE MICROBIOLÓGICA DA FARINHA DAS CASCAS DE OVOS

\begin{tabular}{l|c|c}
\hline \multicolumn{1}{c|}{ Patógeno } & $\begin{array}{c}\text { Farinha de casca } \\
\text { de ovo }\end{array}$ & $\begin{array}{c}\text { Padrão microbiológico } \\
\text { (BRASIL, 2001) }\end{array}$ \\
\hline Coliformes a $45^{\circ} \mathrm{NPM} / \mathrm{g}$ & $<3,0 \mathrm{NPM} / \mathrm{g}$ & $10 \mathrm{NPM} / \mathrm{g}$ (máx) \\
\hline $\begin{array}{l}\text { Estafilococos coagulase } \\
\text { positiva UFC/g }\end{array}$ & $<1,0 \times 10^{2} \mathrm{UFC} / \mathrm{g}$ & $5 \times 10^{2} \mathrm{UFC} / \mathrm{g}$ (máx) \\
\hline Salmonella $\mathrm{sp} / 25 \mathrm{~g}$ & Ausência & Ausência \\
\hline
\end{tabular}

A sanidade microbiológica da farinha de casca de ovos mostra o correto método no seu preparo, visto que o produto é contaminado por natureza, principalmente pela Salmonella sp, patógeno presente no intestino da galinha (SANT'ANA, 2000).

Segundo Oliveira (2009), devido às restrições microbiológicas, a utilização de cascas de ovos para alimentação humana ou animal, deve estar assegurada pelos parâmetros microbiológicos dos produtos e processos.

$\mathrm{Na}$ farinha de casca de ovos elaborada, foram pesquisados os microrganismos recomendados na RDC $n^{\circ} 12$, de 2 de janeiro de 2001 (BRASIL, 2001), conforme podem ser observados na tabela 2 todos os patógenos apresentaram teores inferiores ao recomendado por esta resolução. O que permite uma recomendação de uso desta farinha em produtos alimentícios.

\section{CONCLUSÃO}

A farinha das cascas de ovos apresentou $39,9 \%$ de cálcio biodisponível para o organismo.

A análise microbiológica, não apresentou contaminantes em potencial, validando assim o método de preparo da farinha.

A farinha é segura no aspecto microbiológico e com $39,9 \%$ de cálcio biodisponível pode-se recomendar seu uso para fins alimentícios.

\section{REFERÊNCIAS:}

AACC. American Association of Cereal Chemists Approved methods of the American Association of Cereal Chemists. 9. ed. St. Paul: Approved Methods Committee, v.1 e v.2, 1995.

AOAC. Official methods of analysis of AOAC internacional. 17ed., v.2, 17th ed. Gaithersburg: AOAC, 2000.

ANACONDA. Produtos:Farinha de trigo. Disponível em http://www.anaconda. com.br/index2.php?menu=1\&tipo=Anaconda\&produto Acesso em 30 de maio de 2009, às 18:00.

BRASIL. ANVISA-Agência Nacional de Vigilância Sanitária. Resolução $n^{\circ}$ 12, de 2 de janeiro de 2001 - Regulamento Técnico para Padrões Microbiológicos para Alimentos. Disponível em: http://e-legis.anvisa.gov.br/

leisref/public/showAct.php?id=144. Acesso em 19 mai. 2008.

BRASIL. ANVISA - Agência Nacional de Vigilância Sanitária. Portaria $n^{\circ} \mathbf{3 1}$ de 13 de janeiro 
de 1998 - Regulamento Técnico referente a Alimentos Adicionados de Nutrientes Essenciais. Disponível em: http://e-legis.anvisa.gov.br/leisref/public/showAct.php?id=64. Acesso em 15 jul 2009.

BRYANT R. J., CADOGAN J., WEAVER C. M. The new dietary reference intakes for calcium: implications for osteoporosis. Journal Am Coll Nutr 18(Suppl): 406S-412S, 1999

COZZOLINO, S. M. F.; COLLI, C.; SACHS, A.; CUPPARI, L.; FISBERG, R.M.; MARCHIONI, D. M. L.; SLATER, B. Uso e aplicações das "Dietary Reference Intakes" DRIs. ILSI Brasil, São Paulo/SP, nov. 2001.

DE PAULA, R. A. C. O impacto de um biscoito fortificado com cálcio sobre o estado nutricional e densidade mineral óssea em adolescentes. São Paulo, 2004. 174 f. Tese Doutorado em Ciências - Escola Paulista de Medicina.

GALISA, M. S.; ESPERANÇA, L. M. B. \& SÁ, N. G. Nutrição conceitos e aplicações, São Paulo, $1^{\circ}$ ed, p.65-66, 2008.

GRÜDTNER, V. S.; WEINGRILL, P. \& FERNANDES A. L. Aspectos da absorção no metabolismo do cálcio e vitamina D. Rev. Bras. Reumatologia, Joinville, v. 37, n. 3, p. 143-151, mai/jun 1997.

IAL. INSTITUTO ADOLFO LUTZ. Normas Analíticas do Instituto Adolfo Lutz: métodos químicos e físicos para análise de alimentos. 4 ed. Brasília, 2005.

JOHNSON, L. E. Vitamin and mineral fortification of food. Food Technology, Chicago, v.48, n.7, p.124, 1994.

LUCAS, R.; COSTA L.; BARROS H. Ingestão de Cálcio e Vitamina D numa Amostra Urbana de Mulheres Portuguesas. Arq Méd, Porto, v.19, n.1-2, jan 2005.

LUFT, N. et al. Teor de cálcio e qualidade microbiológica da farinha da casca de ovo. CONGRESSO NACIONAL DA SOCIEDADE BRASILEIRA DE ALIMENTAÇÃO E NUTRIÇÃO, São Paulo: Sociedade Brasileira de Alimentação e Nutrição, 2005. p. 351.

MALNIC, G.; MARCONDES, M. Regulação do metabolismo de cálcio e fósforo. Fisiologia Renal, São Paulo, $3^{\circ}$ ed., p.285-321, 1986.

MURAKAMI, F. S., 2006. Estudo termoanalítico entre carbonato de cálcio industrial e carbonato de cálcio obtido da casca do ovo. $V$ Congresso Brasileiro de Análise Térmica e Calorimetria - V CBRATEC.

MURAKAMI, F. S. et al. Physicochemical study of $\mathrm{CaCo}^{3}$ from egg shells. Ciência e Tecnologia de alimentos, 27(3), 658-662, jul-set, 2007.

NEVES, M. A., Alternativas para valorização da casca de ovo como complemento alimentar e em implantes ósseos. Dissertação de Mestrado em Ciência dos Alimentos. Departamento de 
Ciência e Tecnologia de Alimentos -

Universidade Federal de Santa Catarina, Florianópolis, Brasil, 1998.

NAVES, M. M. V.;FERNANDES, D. C. Fortificação de alimentos com o pó da casca de ovo como fonte de cálcio. Ciência e Tecnologia de Alimentos, Campinas, v. 27, n.1, p.99-103, jan./mar.2007.

NAVES, M.M.V. Pó da casca de ovo como fonte de cálcio: qualidade nutricional e contribuição para o aporte adequado de cálcio. Revista da UFG, vol.5 n 1, abr 2003.

OLIVEIRA, D.A.; BENELLI, P; AMANTE, E.R. Valorização de resíduos sólidos: Casca de Ovos como matéria-prima no desenvolvimento de novos produtos. Second International Workshop Advances in Cleaner Production, São Paulo, mai 2009.

PEDRÃO, M. R. et al. Enriquecimento de preparado sólido para refresco de fruta com cálcio. I Simpósio Internacional de Alimentos Funcionais, 2008, São Paulo. I Simpósio Internacional de Alimentos Funcionais, São Paulo, 2008.

PHILIPPI, S. T. Nutrição e Técnica Dietética. Barueri, SP: Manole, p. 56-66, 2006.

POSSAMAI, T. N. Elaboração do pão de mel com fibra alimentar proveniente de diferentes grãos, sua caracterização físico-química, microbiológica e sensorial. Curitiba, 2005. 69 f. Dissertação (Mestrado em Tecnologia de Alimentos) - Setor de Tecnologia, Universidade Federal do Paraná.

SANT'ANA, L. F R. et al. Valor nutritivo e fatores antinutricionais de multimisturas utilizadas como alternativa alimentar. Braz. J. Food Technol. Preprint Serie, n.45, 2000.

SHILS, M. E. Tratado de nutrição moderna na saúde e na doença. Barueri, SP: Manole, 2003.

SILVA, B. C. C.; CAMARGOS, B. M. C.; FUJII, J. B.; DIAS, E. P. \& SOARES, M. M. S. Prevalência de deficiência e insuficiência de vitamina $\mathrm{D}$ e sua correlação com $\mathrm{PTH}$, marcadores de remodelação óssea e densidade mineral óssea, em pacientes ambulatoriais,. Arquivos Brasileiros de Endocrinologia e Metabologia, São Paulo, v.52, n.3, abr 2008.

SILVA JUNIOR, E. A. Manual de controle higiênico-sanitário em Serviços de Alimentação. $6^{\circ}$ ed. São Paulo: Varela, 2005. 623p.

VACLAVIK, V. A.; CHRISTIAN, E. W. Essentials of food science. Chapter 1: Evaluation of Food Quality. 2 ed. Food Science Text Series, Nova Iorque. 2003. 